\title{
PENGEMBANGAN PERANGKAT PEMBELAJARAN IPA MODEL KOOPERATIF TIPE GROUP INVESTIGATION UNTUK MENINGKATKAN KETERAMPILAN SISWA DALAM MENGAMBIL KEPUTUSAN DI KELAS VII SMP
}

\author{
Intannani Mustikasari ${ }^{1)}$, Endang Susantini ${ }^{2)}$, Wasis ${ }^{3)}$ \\ ${ }^{1)}$ Mahasiswa Program Studi Pendidikan Sains, Program Pascasarjana Universitas Negeri Surabaya \\ ${ }^{2), 3)}$ Dosen Pascasarjana Prodi Pendidikan Sains Univesrtitas Negeri Surabaya \\ E-mail: intannanimustikasari@gmail.com
}

\begin{abstract}
This research aims to produce the teaching materials based on science cooperative Group Investigation model which is valid, practical, and effective to facilitate the students' decision making skill. The development of teaching material used the 4D model and was implemented in 7th-B grade of SMPN 6 Surabaya in the first semester of 2015/2016 by using the PreExperimental One-Group Pretest-Posttest Design. The data collection used validation, observation, quetionnaires, test, and documentation. The data analysis techniques used quantitative and qualitative descriptive analysis. The results of this research are:(1) Teaching material developed to be use consisted of Syllabus, Lesson Plan, Book, Student Worksheet and Test of student learning outcomes are valid; (2) The practicality of teaching material categorized in terms of: (a) The teaching materials categorized in feasibility of lesson plan, (b) The legibility of the student book;(c) The constraints encountered obstacles during the implemantion and (3) The teaching material effectiveness in terms of: (a) Improving students' learning decision making skill by getting gain score in medium category; (b) Improving students' learning achievement by getting score in medium catagory; (c) The students give a positive responses toward teaching material and implementation of teaching material developed . Thus, teaching materials based on science cooperative Group Investigation model are valid, practical, and effective to facilitate the students' scientific decision making skill in VII grade of Junior High School.
\end{abstract}

Keywords: Science Teaching Materials, Group Investigation, Decision Making Skill.

Abstrak: Penelitian ini bertujuan untuk menghasilkan perangkat pembelajaran IPA model kooperatif tipe Group Investigation yang valid, praktis dan efektif untuk meningkatkan keterampilan siswa dalam mengambil keputusan. Pengembangan perangkat pembelajaran menggunakan model 4-D dan diujicobakan di Kelas VII-B SMPN 6 Surabaya pada semester ganjil tahun ajaran 2015/2016 dengan One-Group Pretest-Posttest Design. Pengumpulan data menggunakan metode validasi, observasi, angket, dokumentasi, dan tes. Teknik analisis data menggunakan analisis deskriptif kuantitatif dan kualitatif. Hasil penelitian ini menunjukkan: (1) Perangkat pembelajaran yang dikembangkan meliputi Silabus, RPP, Bahan Ajar Siswa, LKS, dan Lembar Penilaian berkategori valid; (2) Perangkat pembelajaran berkategori praktis ditinjau dari: (a) Keterlaksanaan RPP, (b) Keterbacaan bahan ajar siswa, (c) Kendala-kendala yang dijumpai selama proses KBM; serta (3) Perangkat pembelajaran telah efektif ditinjau dari: (a) Peningkatan nilai keterampilan siswa dalam mengambil keputusan siswa dengan perolehan skor $n$-gain pada kategori sedang, (b) Peningkatan nilai pengetahuan dengan perolehan skor n-gain pada kategori sedang, (c) Siswa merespon positif perangkat yang dikembangkan dan implementasinya. Berdasarkan hasil analisis data dapat disimpulkan bahwa perangkat pembelajaran IPA model kooperatif tipe Group Investigation yang digunakan valid, praktis, dan efektif untuk meningkatkan keterampilan siswa dalam mengambil keputusan di kelas VII SMP

Kata kunci: Perangkat Pembelajaran IPA, Group Investigation, Keterampilan Mengambil Keputusan

\section{PENDAHULUAN}

Ilmu Pengetahuan Alam (IPA) berkaitan dengan cara mencari tahu tentang gejala alam secara sistematis, sehingga IPA bukan hanya penguasaan kumpulan pengetahuan yang berupa fakta-fakta, konsep-konsep, atau prinsip-prinsip saja tetapi juga merupakan suatu proses penemuan. Uraian tersebut, sesuai dengan tujuan dari Kurikulum 2013 (Kemendikbud, 2013), yaitu untuk mendorong siswa mampu lebih baik dalam melakukan observasi, bertanya, bernalar, dan mengkomunikasikan apa yang mereka peroleh atau mereka ketahui setelah menerima materi pembelajaran. Siswa diharapkan memiliki kompetensi sikap, keterampilan, dan pengetahuan yang lebih baik sehingga siswa akan lebih kreatif, inovatif, produktif, dan dapat sukses dalam menghadapi berbagai persoalan 
dan tantangan di zamannya. Harapan tujuan yang terpapar dalam Kurikulum 2013 memiliki kesesuaian dengan kegiatan penyelidikan (investigation).

Kegiatan penyelidikan (investigation) merupakan kegiatan di dalam kegiatan belajar mengajar di dalam kelas yang berpusat pada peserta didik di mana peserta didik melakukan penyelidikan dengan mencari jawaban-jawaban terhadap isi pertanyaan melalui suatu prosedur yang digariskan secara jelas dan struktural yang dilakukan di dalam suatu kelompok belajar. Campbell et al., (1997) menyatakan bahwa siswa yang belajar IPA dengan cara metode investigation tidak hanya sekedar menghafal informasi, tetapi juga menggunakan pemikiran ilmiah untuk mengambil keputusan dalam kehidupan sehari-hari.

Berdasarkan penjabaran di atas, kegiatan penyelidikan sangat cocok digunakan pada model pembelajaran kooperatif tipe Group Investigation untuk meningkatkan keterampilan siswa dalam mengambil keputusan. Model pembelajaran, Group Investigation sangat baik diimplementasikan guna meningkatkan keterampilan siswa dalam mengumpulkan informasi untuk memecahkan masalah serta meningkatkan kecakapan berpikir tingkat tinggi siswa.

Berpikir Tingkat Tinggi (High Order Thinking) melibatkan penggalian makna dan penemuan pola dalam ketidakteraturan, serta melibatkan pertimbangan yang seksama dan interpretasi (Resnick, 1987). Woolfolk (1997) menyatakan bahwa keterampilan berpikir tingkat tinggi meliputi keterampilan pemecahan masalah, keterampilan berpikir kritis, keterampilan berpikir kreatif, dan keterampilan mengambil keputusan.

Keterampilan berpikir tingkat tinggi khususnya keterampilan mengambil keputusan sangat penting diajarkan di sekolah, karena menurut Santrock (2006) pengambilan keputusan adalah sebuah pemikiran di mana individu mengevaluasi berbagai pilihan dan memutuskan sendiri dari sekian banyaknya pilihan yang tersedia. Maka dari itu siswa perlu didorong agar terampil dalam mengambil suatu keputusan untuk mempertimbangkan cara dalam menyelesaikan suatu permasalahan.

Berdasarkan uraian di atas, perlunya membekali siswa pada jenjang SMP dengan pembelajaran IPA yang bermakna dan pengalaman langsung dapat melatih meningkatkan keterampilan berpikir tingkat tinggi siswa dalam mengambil suatu keputusan untuk menyelesaikan suatu permasalahan.

Salah satu alternatif agar siswa dapat mengembangkan keterampilan mengambil keputusan, yaitu dengan mengembangkan perangkat pembelajaran IPA model kooperatif tipe Group Investigation. Berdasarkan uraian latar belakang tersebut, maka dirumuskan suatu judul penelitian sebagai berikut:
"Pengembangan Perangkat Pembelajaran IPA Model Kooperatif Tipe Group Investigation untuk Meningkatkan Keterampilan Siswa dalam Mengambil Keputusan di Kelas VII SMP".

\section{METODE PENELITIAN}

Penelitian ini merupakan jenis penelitian pengembangan, yaitu pengembangan perangkat pembelajaran IPA model kooperatif tipe Group Investigation untuk meningkatkan keterampilan siswa dalam mengambil keputusan. Pengembangan yang akan dilakukan mengacu pada model pengembangan 4-D (four $D$ models). Hal ini dikarenakan pengembangan perangkat pembelajaran dengan four-D model memiliki tahapan pengembangan yang lebih lengkap dan lebih runtut. Model pengembangan 4-D terdiri dari 4 tahap, yaitu tahap pendefinisian (define), tahap perencanaan (design), tahap pengembangan (develop) dan tahap penyebaran (disseminate)

\section{HASIL PENELITIAN DAN DISKUSI}

Data yang diperoleh dalam penelitian ini dapat dijabarkan sebagai berikut: (1) Perangkat pembelajaran yang dikembangkan meliputi Silabus, RPP, Bahan Ajar Siswa, LKS, dan Lembar Penilaian berkategori sangat valid; (2) Perangkat pembelajaran berkategori praktis ditinjau dari: (a) Keterlaksanaan RPP memiliki kategori baik dengan rata-rata reliabilitas sebesar $97.39 \%$, (b) Keterbacaan bahan ajar siswa memiliki katagori sedang, (c) Kendala-kendala yang dijumpai selama proses KBM sudah memiliki solusi alternatif; serta (3) Perangkat pembelajaran telah efektif ditinjau dari: (a) Peningkatan nilai keterampilan siswa dalam mengambil keputusan siswa dengan perolehan skor n-gain pada kategori sedang, (b) Peningkatan nilai pengetahuan dengan perolehan skor n-gain pada kategori sedang, (c) Siswa merespon positif perangkat yang dikembangkan dan implementasinya.

\section{KESIMPULAN}

\section{A. Simpulan}

Berdasarkan hasil analisis, diskusi, dan pembahasan, maka dapat dibuat kesimpulan bahwa:

1. Perangkat pembelajaran IPA model kooperatif tipe Group Investigation untuk meningkatkan keterampilan siswa dalam mengambil keputusan di kelas VII SMP yang dikembangkan sudah valid.

2. Perangkat pembelajaran IPA model kooperatif tipe Group Investigation untuk meningkatkan keterampilan siswa dalam mengambil keputusan di kelas VII SMP yang dikembangkan sudah praktis, ditinjau dari:

a. Keterlaksanaan Rencana Perangkat Pembelajaran (RPP) selama proses pembelajaran dengan menggunakan perangkat pembelajaran IPA model kooperatif tipe Group Investigation 
yang dikembangkan memiliki katagori sangat baik.

b. Keterbacaan bahan ajar siswa model kooperatif tipe Group Investigation yang dikembangkan memiliki tingkat keterbacaan sedang.

c. Kendala-kendala yang dijumpai selama proses pembelajaran IPA model kooperatif tipe Group Investigation yang dikembangkan telah dibuat solusi alternatif atas kendala-kendala yang ditemukan.

3. Perangkat pembelajaran IPA model kooperatif tipe Group Investigation untuk meningkatkan keterampilan siswa dalam mengambil keputusan yang dikembangkan sudah efektif, ditinjau dari:

a. Tingkat keterampilan siswa dalam mengambil keputusan setelah menggunakan perangkat pembelajaran IPA model kooperatif tipe Group Investigation yang dikembangkan memiliki skor peningkatan n-gain dengan katagori sedang.

b. Hasil belajar keterampilan siswa dalam mengambil keputusan setelah diterapkannya perangkat pembelajaran IPA model kooperatif tipe Group Investigation yang dikembangkan mengalami peningkatan ketuntasan belajar.

Respon siswa terhadap perangkat pembelajaran IPA model kooperatif tipe Group Investigation yang dikembangkan adalah positif.

\section{B. Saran}

Beberapa saran dapat dikemukakan oleh peneliti berdasarkan penelitian yang telah dilakukan adalah sebagai berikut:

1. Penerapan rencana pelaksanaan pembelajaran sudah baik namun guru harus lebih dapat mengelola waktu selama pembelajaran agar pembelajaran bias berjalan lebih efektif dan efisien. Disarankan peneliti-peneliti selanjutnya memberikan gambaran dengan jelas kepada siswa dan guru tentang pembelajaran menggunakan model kooperatif tipe Group Investigation.
2. Pengenalan keterampilan siswa dalam mengambil keputusan dilakukan pada waktu khusus, agar saat proses pembelajaran siswa tidak kesulitan menyelesaikan LKS dan melakukan penyelidikan.

3. LKS dan bahan ajar siswa yang digunakan pada saat pembelajaran lebih baik dibagikan kepada siswa sebelum pembelajaran dilaksanakan sehingga siswa lebih mudah dalam memahami LKS tersebut.

Secara keseluruhan pengembangan perangkat pembelajaran IPA model kooperatif tipe Group Investigation dapat meningkatkan keterampilan siswa dalam mengambil keputusan, sehingga diharapkan untuk penelitian lanjutan pada materi IPA lainnya dilengkapi dengan media pembelajaran yang lebih memudahkan siswa dalam memahami materi pembelajaran.

\section{REFERENSI}

Campbell, Vincent.,Loftstrom, Jocelyn., Jerome, Brian. (1997). Decisions Based on Science. Arlington VA: National Science Teachers Association.

Kemdikbud. (2013). Peraturan Menteri Pendidikan dan Kebudayaan, Nomor 32 Tahun 2013 tentang Standar Nasional Pendidikan. Jakarta: Pusat Kurikulum dan Perbukuan, Balitbang, Kemdikbud.

Resnick, L.B. (1987). Education and Learning to Think. Committee on Research in Mathematics, Science, and Technology Education. Tersedia: National Academies Press at: http://www.nap.edu/catalog/1032.html.

Santrock, John W. (2006). Educational Psychology Third Edition. New York: McGraw-Hill.

Woolfolk, Anita E. (1997). Educational Psychology Fifth Edition. Boston: Allyn and Bacon. 